\title{
Microbial Lipases: A Prospect for Biotechnological Industrial Catalysis for Green Products: A Review
}

Agbo Ken Ugo ${ }^{1 *}$, Arazu Vivian Amara ${ }^{1}$, Uzo Kenechuwku ${ }^{1}$ and Igwe $\mathrm{CN}^{2}$

${ }^{1}$ Department of Biochemistry, University of Nigeria, Nsukka, Enugu State, Nigeria

${ }^{2}$ Department of Pure and Industrial Chemistry, University of Nigeria, Nsukka Enugu State, Nigeria

*Corresponding author: Agbo Ken Ugo, Department of Biochemistry, University of Nigeria, Nsukka, Enugu State, Nigeria, Tel: +2347039865023; E-mail: kenagbo6@gmail.com

Received date: June 28, 2017, Accepted date: July 28, 2017, Published date: August 09, 2017

Copyright: (c) 2017 Ugo AK, et al. This is an open-access article distributed under the terms of the Creative Commons Attribution License, which permits unrestricted use, distribution, and reproduction in any medium, provided the original author and source are credited.

\begin{abstract}
Microbes have been novel hosts for suitable industrial enzymes including lipases. With the rapid increase in biotechnological industries, there is need for improvement of bioproducts, enhance environmental safety and product yield. Microbes are qualified biological arsenal for the achievement of the above mentioned targets in the industrial sectors. Lipases as versatile biological catalyst has given a promising prospect in meeting the needs for most industries such as biodiesel, foods and drinks, leather, textile, detergents, pharmaceuticals and medicals. Catalytic importance of lipases includes hydrolysis, esterification and transesterification. Each of the mentioned reactions has their industrial applications. Lipases exhibit various properties, with respect to its source. Immobilization has made the use of microbial lipases attain its optimum performance and hence suitable for various reaction and the need to add flavor to the immobilization processes.
\end{abstract}

Keywords: Digestive enzymes; Catalysts; Vegetable oil

\section{Introduction}

Humans are now interested in nature's mimic for most industrial processes, especially in bringing a high product yield in a short given time and mild conditions. Most industrial processes lead to unwanted by-products under chemical catalysis, which may be very hazardous for human consumption. There is then the need for production of the targeted products, which are expected to be less toxic and costs little or nothing for product separation. In addition, some industrial processes may lead to high energy consumption thereby subjecting the globe to an increased entropy which has its own unfavorable results to humans. Good industrial practices are expected to be:

- Environmental friendly

- Yield of less toxic substances

- Fast and high product yielding

- Produce the expected products

- Cost effective (i.e. economical)

With the discovery of digestive enzymes, it was observed that the body makes use of enzymes for production and degradation of its targeted products or substances minimize the energy of reaction and also facilitate its reactions. Enzymes are considered nature's catalysts [1], or biocatalyst produced by living cells to bring about specific biochemical reactions generally forming parts of the metabolic process of cell [2]. The enzymes are not only the parts of metabolic process of the cells but also widely used in industrial processes due to their low cost, large productivity, chemical stability, environmental protection, plasticity and vast availability [3].

Enzymes are proteins, which act as a catalyst, and thereby lower the energy required for the reaction they catalyze without being used in the reaction. There are many types of industries that utilize enzymes to aid in the generation of their products. The industrial enzyme producers produce enzymes for wide variety of applications. The estimated value of world's enzyme market is presently $\$ 2.7$ billion and estimated to increase by $4 \%$ annually [4]. The enzyme industry today is the result of rapid development seen primarily over the past four decades due to the biotechnological approach [5]. The main industries that apply microbial enzymes are the food, textile, leather, pharmaceuticals, cosmetics, fine chemicals, energy, biomaterials, paper, cellulose and detergents industries. The development of fermentation processes during the latter part of the last century, revealed the production of enzymes by use of selected strains, made it possible to manufacture enzymes as purified, well-characterized preparations and even on a large scale by using industrial methods [6].

Microbial enzymes have some quite attractive advantages over plant and animal enzymes, which includes:

\section{Sustainability}

Microbial enzymes can be produced at any time and are not affected by seasonal fluctuations [7].

\section{Less or no ethical concerns}

The use of microbes has little or no ethical issues. Destroying animals or plants for the sake enzyme production will result to food insecurity and subsequently, nutritional problems, which may lead to death.

\section{Availability/Economical}

The other advantages of microorganisms over plants and animals are that they can grow rapidly and on an inexpensive media. As their growth is rapid, so their secretion of enzymes [7]. 


\section{Stability}

Microbial enzymes are more stable in terms of activity [8], also microbial enzymes can withstand harsh conditions such as heat, $\mathrm{pH}$ and chemicals over a wide range of time. Industrial processes take place at a high temperature to avoid contamination risk and reduce reaction time, thus saving considerable amount of energy [9].

\section{Portability/Ease of handling}

Microbes are easy to handle when compared to animals and plants. They require lesser space [10].

\section{Genome stability}

The simplicity of microbial genome has been exploited in production of enzymes. Microbes can easily be induced to produce any enzyme of interest with desired properties by manipulating the gene either by rDNA technology or catabolite inducers [10].

Lipases (triacylglycerol acylhydrolases, EC 3.1.1.3) catalyze the hydrolysis and synthesis of esters from glycerol and long-chain fatty acids. Lipases occur widely in nature, but only microbial lipases are commercially significant. Importance of microbial enzymes has been discussed. Lipase producing microbes have been found in diverse habitats such as industrial wastes where they play major roles in waste biotransformation, vegetable oil processing factories where they catalyse breaking down of lipids into glycerol and free fatty acids, dairies, soil contaminated with oil, etc [11]. structural conservation is a very valuable tool helping in the classification of newly identified proteins even in the absence of clear sequence similarity. Moreover, it facilitates modelling approaches prior to protein engineering experiments [12].

The original description of this fold was based on the comparison of the three-dimensional structures of hydrolases mostly unrelated in primary sequence and active on substrates very different in structure, one of which was fungal lipase [13]. All lipases whose 3D structures were later solved were found to be members of this folding family [12]. The design of the canonical $\alpha / \beta$ hydrolase fold is based on a central, mostly parallel $\beta$-sheet of eight strands with the only strand $\left(\beta_{2}\right)$ antiparallel. Strand $\beta_{3}$ to $\beta_{8}$ are connected by a-helices packed on both sides of the $\beta$-sheet. Variations from the canonical fold can affect the number of $\beta$-strands, the presence of insertions and the architecture of the substrate binding domain [12], which results to the so-called promiscuous nature of lipases. In $\alpha / \beta$ hydrolases, the active site consists of a catalytic triad comprising a nucleophile, the acidic residue and a histidine, reminiscent of that serine protease but with a different order in the sequence: nucleophile-acid-histidine [13]. The lipase catalytic triad is composed of serine, aspartate or glutamine and histidine with the serine enclosed in the consensus motif which forms a sharp turn (the nucleophilic elbow) in a strand-turn-helix motif in strand $\beta_{5}$ which forces the nucleophile to adopt unusual main chain $\phi$ and $\psi$ torsion angles. Due to its functional relevance, the nucleophilic elbow is the most conserved feature of the fold.

\section{3-D Structure of Lipases}

All lipases display the same structural architecture, the so-called a/ $\beta$ - hydrolase fold and have identical catalytic machineries. Such

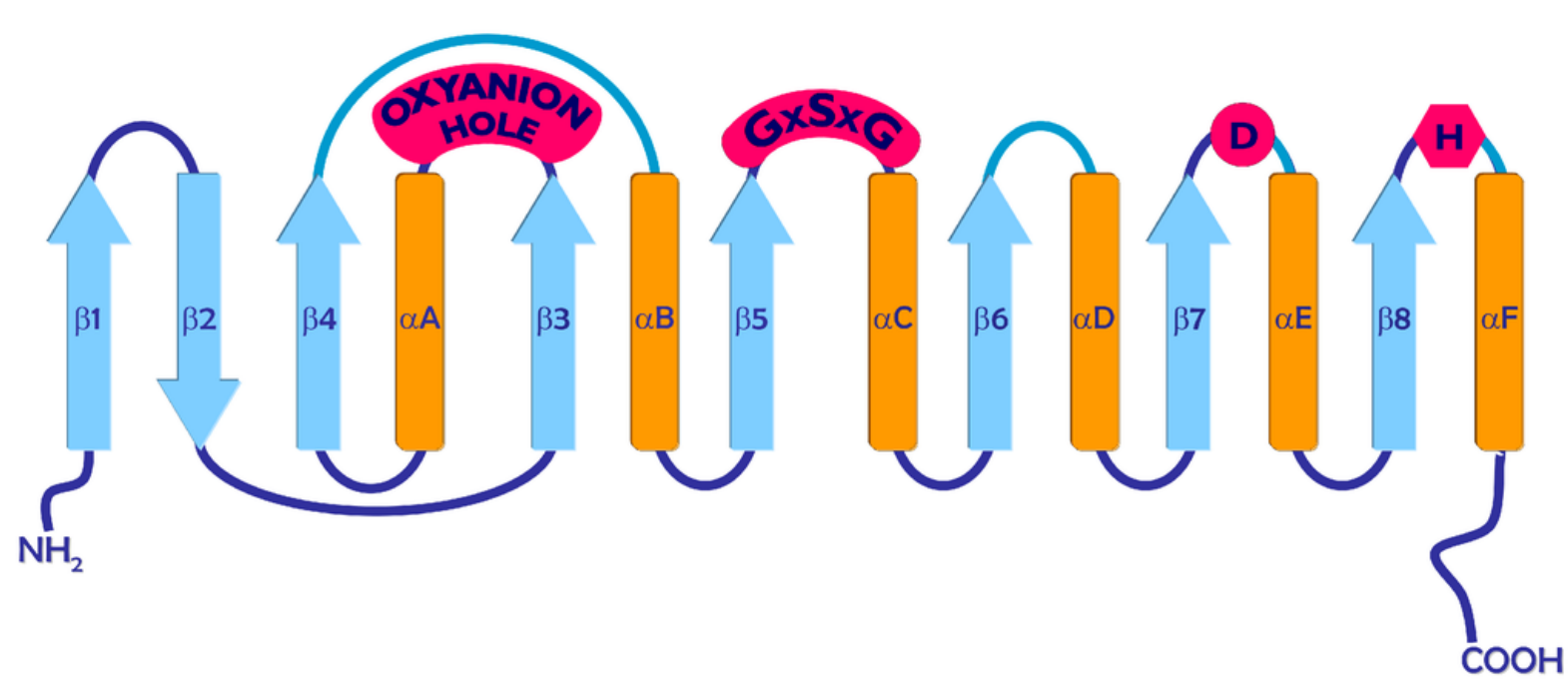

Figure 1: 1 Canonical fold of $\alpha / \beta$ hydrolases. Strands are indicated by arrows and helices by cylinders. The positions of the histidine $(\mathrm{H})$ and aspartate (D) residues, as well as the GXSXG and the oxyanion hole are shown [14].

\section{Catalytic Mechanism of Lipases}

Hydrolysis of substrates follows two step mechanisms:

\section{Acylation}

The nucleophilicity of the active serine enhanced by abstracting a proton to the catalytic histidine with the formation of an oxyanion that attacks the carbonyl carbon of the targeted ester bonds. The attack will 
result in the formation of an unstable tetrahedral intermediate carrying a (negatively) charged oxygen atom on the carbonyl carbon and release of alcohol. The unstable intermediate is then stabilized by the means of hydrogen bonding to the main chain $\mathrm{NH}$-groups of the so-called oxyanion hole. In some lipases, the oxyanion hole is performed in the correct orientation, whereas in others it is positioned upon the opening of the "lid" structure [12]. The proton on the histidine is then transferred to the serine-oxygen (i.e acid catalysis) which brings about cleavage of the serine-substrate bond and formation of the serine and covalent intermediate is formed between the substrate and the $\mathrm{N}$ group of the oxyanion hole residues. This is called acylation step.

\section{Deacylation}

The enzyme-fatty acyl group is hydrolyzed as follows:

Splitting of water $\left(\mathrm{H}_{2} \mathrm{O}\right)$ molecules will result in the formation of protons and hydroxyl ion. The proton then attacks the Nu-group of the oxyanion hole since it becomes nucleophilic on undergoing a heterolytic fission, resulting in the formation of $\mathrm{Nu}-\mathrm{H}$. The hydroxyl ion will then attack the released unstable acyl molecules resulting in the formation of fatty acid and free enzyme (regained conformation). In essence, the serine plays a role of substrate binder or holder, the histidine is responsible for the actual acid catalysis while the aspartic or glutamic acid stabilizes the histidine.

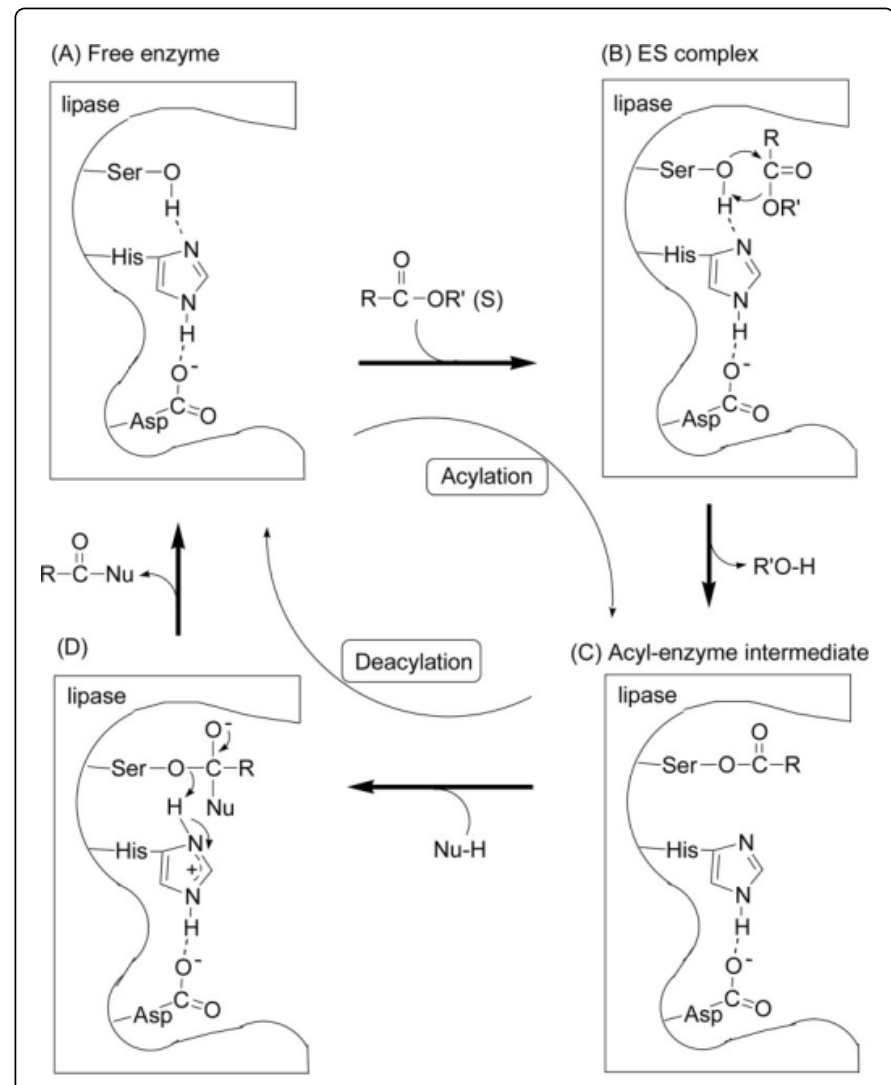

Figure 2: Catalytic mechanism of lipases [15].

\section{Interfacial Activation of Lipases}

Lipases exhibit two conformations depending on the environment they are: One conformation is "close" and the other is "open" conformation. The 3-D structure of some lipases contains an amphiphatic structures called the "Lid". The lid contains both hydrophilic and hydrophobic faces. The hydrophilic face makes contact with water environment while the hydrophilic face is buried in the core of the protein structure. In the absence of the substrate (triglycerides), the enzyme will exhibit the so-called "closed" conformation by exposing its hydrophobic face. When triglyceride is introduced into the environment resulting to a substrate interface, there will be a signal to the active site leading to the exposure of the hydrophobic face (open conformation) and allowing the entrance of the substrate into the active site. This will subsequently result to catalysis [12].

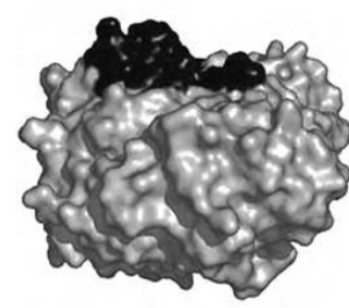

a

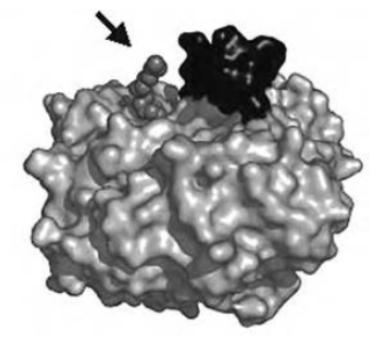

b
Figure 3: Conformational changes in lipases in the presence and absence of substrate [12]. (a) The enzyme exhibits a closed conformation in the absence of the substrate. (b) In the presence of the substrate, the lid will be opened and the enzyme then assumes a new conformation, which makes it an active enzyme.

\section{Lipase-Producing Microorganisms}

Lipase-producing Microorganisms belongs to bacteria, fungi, yeasts and actinomyces. The lipases found among these microbial sources are quite diverse and typically vary from one another in physical, chemical and biological properties [7]. The table below gives a summary of lipase-producing microbes.

\section{Screening and Isolation of Lipase-Producing Microbes}

The underlying principle employed in detection of microbial lipase has always been based on the estimation of free fatty acids liberated from triglycerides after suitable incubation time [36]. The uncertainties in the type of substrates have always been a problem in lipase studies. These uncertainties are also related in the screening techniques proposed. Screening of lipase producers on agar plates using tributyrin as the substrates has been reported [5,37]. Appearance of a clear zone on the plate indicates lipolytic activities of the screened organism. Tributyrin is not considered a lipase substrate, but it does disperse easier in water. The clear zone produced on trybutyrin plate due to trybutyrin hydrolysis is however unclear particularly with low lipase producers [36]. 
Citation: Agobo KU, Arazu VA, Uzo K, Igwe CN (2017) Microbial Lipases: A Prospect for Biotechnological Industrial Catalysis for Green Products: A Review. Ferment Technol 6: 144. doi:10.4172/2167-7972.1000144

Page 4 of 12

\begin{tabular}{|c|c|}
\hline Source & Ref \\
\hline Vibrio fischeri & [16] \\
\hline Thermophilic anoxybacillus falvithermus & [17] \\
\hline Microbacterium sp. & [5] \\
\hline Pseudomonas aeruginosa SRT9 & [18] \\
\hline Actinetobacter radioresistens & [19] \\
\hline Aeromonas hydrophila & [20] \\
\hline Aeromonas sp. & [21] \\
\hline Aspergillus oryzae & [19] \\
\hline Candida antarctica & [22] \\
\hline Pseudoateromonas $s p$ & [23] \\
\hline Pseudomonas alcaligens & [19] \\
\hline Pseudomonas cepacia & [24] \\
\hline Thermotoga sp. & [25] \\
\hline Thermomyces lanuginosus & [22] \\
\hline Aeromonas $s p$ & [26] \\
\hline Acinetobacter baylyi & [27] \\
\hline Pseudomonas aeruginosa $P s-X$ & [28] \\
\hline Pseudomonas aeruginosa EF2 & [29] \\
\hline Bacillus sp RS-12 & [30] \\
\hline Streptococcus lactis & [11] \\
\hline Chromobacterium viscosum & [31] \\
\hline Aspergillus niger & [32] \\
\hline Aspergillus nidulans & [33] \\
\hline Candida rugosa & [34] \\
\hline Streptomyces cinnamomeus & [35] \\
\hline
\end{tabular}

Table 1: Microbial hosts of lipases.

Another method utilizes triolein. Getting triolein to stay in suspension is a problem and emulsifiers maybe required [36]. A method has been considered with triolein as substrate and with rhodamine as indicator [38]. The fluorescent effect on rhodamine B indicated lipid hydrolysis. This technique seems to be more difficult in practice because the fluorescent effect is inconsistent even when tested with known lipase producers [37] shows their unreliability (i.e. falsepositive test the case may be).

A simple and reliable method for detecting lipase activity in microorganisms has been described by Sierra [39]. This method uses the surfactant, tween 80 in a solid medium to identify a lipolytic activity. The formation of opaque zones around the colonies is an indication of lipase producing organisms. Tween 80 has also been used as a substrate with Nile blue as indicator [40]. Initial tests showed that clearance is unclear and this method could be improved using the same surfactant tween 80 as a substrate and Victoria Blue as an indicator [36]. This technique is more simple and reliable when compared to the ones previously discussed.

Olive oil has also been reported as a suitable substrate for screening of lipolytic microorganisms [41].

\section{Lipase Activity Assay}

Lipase activity in microbial supernatant is determined by hydrolysis of p-Nitrophenylesters of long fatty acids with various chain lengths and spectrophotometric detection of p-Nitrophenol at $410 \mathrm{~nm}$. This substrate is called a chromogenic substrate as it undergoes hydrolysis in the presence of lipase to generate p-nitrophenol, which has a yellow color and fatty acid. Lipase activity has been measured using $\mathrm{p}$ Nitrophenyl laurate (pNPL) [17]. In another report, lipase activity was also measured using p-Nitrophenyl Palmitate (pNPP) [5]. 


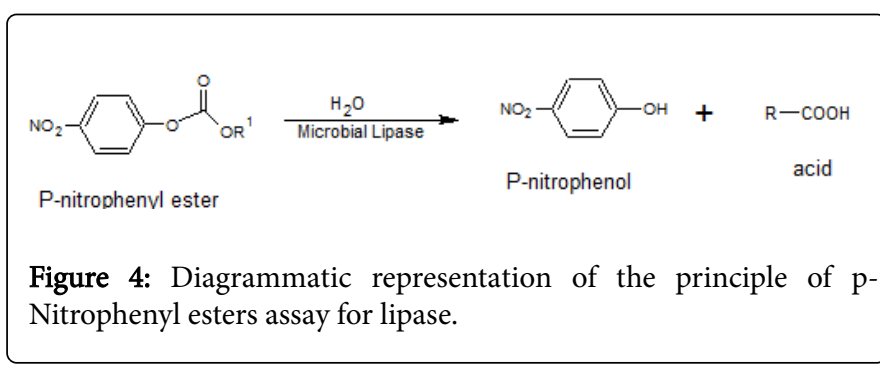

Unfortunately, this method is very simple but not that reliable one since esterases also has hydrolytic ability on p-Nitrophenyl esters. So one may not actually differentiate if the activity is that of esterase or lipase. A more reliable but laborious method is the titrimetric assay for lipases [42]. The use of this method has been effectively reported in the measurement of true lipase by $[36,41]$.

\section{Optimization of Fermentation Condition for Production of Microbial Lipases}

Fermentation conditions affect to a large extent the enzyme yield by any microorganism. To ensure a high yield of the enzyme, the condition for the fermentation must be exploited. These conditions are: $\mathrm{pH}$, carbon source, Nitrogen source, Temperature, speed of agitation, period of fermentation, etc.

\section{Effect of carbon sources}

Three carbon sources (tributyrin, olive oil and glucose) were tested for on the production yield of bacterial lipase from Bacillus subtilis KPL13 isolated from soil samples of Kolli hills, south India. It was observed that the maximum production was recorded using olive oil then tributyrin and lowest, glucose. Some carbohydrate molecules were also used as an additional carbon sources for microbial lipases production. These carbohydrates are maltose, starch, lactose, mannose and galactose while olive served as control. It was observed that none increased the production of lipase compared to the control [43].

Effect of various oils on the lipase production from bacteria was studied. Palm oil showed the highest production followed by olive oil Ghee had the lowest yield [44].

\section{Effect of nitrogen sources}

Ammonium dihydrogen phosphate, yeast extract and peptone were employed in the production of lipase from Bacillus subtilis KPL13. Peptone exhibited activity of $3.7 \mu / \mathrm{ml}$, yeast exhibited $2.0 \mu / \mathrm{ml}$ while ammonium dihydrogen phosphate had the lowest activity with an activity of $0.8 \mu / \mathrm{ml}$. This is an indication that organic nitrogen source may be a suitable nitrogen source for high production of lipase from the organism.

Some amino acids were used as an additional nitrogen source for the production of lipase from Pseudomonas gessardii as was reported by Veerapagu et al. [43]. Among the 10 amino acids, Histidine, lysine and arginine influenced lipase production. On the other hand, aspartic acid, tryptophan, valine, glutamine and alanine caused a considerable reduction in enzyme production. A boosting effect of organic nitrogen sources has been reported. Proteose peptone and peptone have also been reported to increase the production of lipase whereas lipase production was very low with casein, soy bean meal and soy peptone.
Similarly, inorganic nitrogen sources, ammonium sulphate and ammonium chloride enhanced the lipase production but not as good as the organic sources with the maximum activity.

Among the different nitrogen sources used, peptone $(2 \mathrm{~g} / \mathrm{l})$ was found to be the most suitable source for maximum lipase production [45].

Effect of soybean meal, tryptone, peptone, yeast extract and sodium nitrate on lipase production by Bacillus $s p$. was also studied. As expected, peptone had the maximum production followed sequentially by tryptone, soybean meal, yeast extract with $\mathrm{NaNO}_{3}$ having the lowest yield of the enzyme [44]. This still supports that organic sources of nitrogen remain the most suitable for microbial lipase production.

\section{Effect of temperature}

Effect of temperature on the production of lipases is necessary as it affects the thriving of the organism in the fermentation media. A suitable temperature of $36^{\circ} \mathrm{C}$ was reported for the production of lipase from Bacillus sp. [44]. A similar result was reported by [46] on lipase production by Pseudomonas fluorescence NS2W. A very close temperature value $\left(35^{\circ} \mathrm{C}\right)$ was also recorded by the same species of bacteria. At the temperature of $37^{\circ} \mathrm{C}$, Pseudomonas gessardii isolated from oil spilled soil had the maximum lipase production [43]. A similar result was reported by Pseudomonas xinjiangensis [47] and by Staphylococcus [37].

\section{Effect of $\mathbf{p H}$}

The initial $\mathrm{pH}$ of the growth medium influences the rate of lipase production. It was also inferred from the results that bacteria is capable of producing lipase from the initial $\mathrm{pH}$ of medium from $\mathrm{pH}$ of 4.0 to $\mathrm{pH}$ 10.0. Pseudomonas gessardii had a maximum lipase production at $\mathrm{pH}$ of 7.0 [43]. A similar result was also reported by Staphylococcus [37]. $\mathrm{pH}$ of 6.0 gave a maximum lipase production by Bacillus subtilis KPL13. A pH of 7.0 was reported as the most suitable $\mathrm{pH}$ for the maximum production of microbial lipases from Bacillus sp. [44].

\section{Effect of agitation speed}

The effect of agitation speed in microbial lipase production is obvious with the evidence provided by some works. To a large extent, agitation increased lipase production and this is attributed to the fact that agitation increased oxygen transfer rate, increased surface area of contact with the media components and better dispersability of the oil substrate during fermentation under agitation condition $[48,49]$. Agitation rate within the range of $110 \mathrm{rpm}$ to $160 \mathrm{rpm}$ enhanced the lipase production by Pseudomonas gessardii. The optimum agitation speed was $160 \mathrm{rpm}$ for this organism [43]. A similar result was obtained by a similar species as was reported by Priya et al. [44]. A

bacterial genus, Staphylococcus was also reported to have its maximum lipase production at $160 \mathrm{rpm}$ [37].

\section{Effect of incubation period}

In lipase production, incubation time plays a pivotal role. An incubation period of 4 days under submerged fermentation was found to be optimum for the production of lipase by Rhizopus sp. ZAC3 isolated from the contaminated soil of a palm oil producing shed [50]. A similar incubation time was reported for maximum lipase 
production in Fusarium solani FS1 [51], in Rhizopus arrhizus [52], in Penicillum notatum [53], in Ganoderma lucidium [54] and in Emericella nidulans NFCCI 3643 [55]. Meanwhile incubation time of 3 days was reported for maximal lipase production in Rhizopus chinensis [56] and Aspergillus niger MTCC 2594 [57]. Maximum production of lipase was obtained at 48 hours by Pseudomonas gessardii [43]. A similar result was obtained by Staphylococcus [37] and Trichoderma viride. However, maximum production of lipase was obtained by Bacillus coagulans at 72 hours [58] and Bacillus of another strain [44].

\section{Purification of Lipases}

Lipases have been purified for different purposes ranging from industrial application, medical uses, the 3-D studies. Depending on the purpose for the purification, some factors such as its degree of purity, cost and properties such as temperature and $\mathrm{pH}$ stability may be considered. There have been non-specific techniques for the purification of lipase though the following general methods could be used to purify lipases such as extraction, precipitation, hydrophobic interaction chromatography, gel filtration and ion exchange chromatography.

Bakir and Metin [17] purified an alkali-thermostable lipase from thermophilic Anoxybacillus flavithermus HBB 134 by a combination of precipitation, dialysis, ion exchange chromatography and finally, gel filtration using sephadex G100. Lipase from Pseudomonas aeruginosa was purified by the integration of precipitation, dialysis, ion exchange chromatography and finally dialysis [41].

Lipase produced by microbacterium $s p$. was purified by a combination of precipitation, dialysis and gel filtration [5].

Affinity chromatography and dialysis were used to purify intracellular lipase B expressed in E. coli to homogeneity [59], while the same steps were used as well to purify recombinant intracellularly expressed thermostable lipase A from Serretia marcescens [60]. A combination of precipitation, ion exchange and fast performance liquid chromatography was employed in the purification of extracellular lipase from the riboflavin overproducing fungus Eremothecium ashbyii [61].
Dialysis or gel filtration chromatography is always followed up after ion exchange chromatography step may be to desalt (i.e. salts used in the elution) the enzyme and subsequently regains its activity.

\section{Enzyme Characterization}

For the context of this work, lipases would be characterized based on:

- Molecular properties

- Physical properties

- Chemical properties

- Kinetic properties

\section{Molecular Properties}

Molecular properties of proteins could be studied by the means of molecular weight and subunits determination.

Molecular weight of enzymes has been a successful analytical tool for protein characterization. The molecular weight of protein can be determined by gel or size exclusion chromatography and native SDSPAGE. Though the two methods have different protocols, they operate in the same principle, which is the "protein mobility". Mobility of proteins is influenced by the charge, size and shapes of the protein.

\section{Determination of molecular weight of lipase by native SDS- PAGE technique}

SDS-PAGE is one of the principal methods of separating proteins. SDS-PAGE separates proteins based on their differences in molecular weight. SDS is an anionic surfactant, which denatures proteins, making them loose their charges and shapes hence making the mobility of the proteins to depend only on their molecular weights. The protocol of SDS-PAGE has been reported by Laemmli [62].

The table below shows the molecular weights and numbers of subunits of various microbial lipases as determined by SDS-PAGE and gel chromatography.

\begin{tabular}{|c|c|c|c|c|}
\hline & Molecular Weight & Isoforms & Source & Ref \\
\hline 1 & a15.5(I) \& 54.97(II) & 2 & $P$. aeruginosa $P S-X$ & [28] \\
\hline 2 & $a_{40.14}$ & 1 & Bacillus sp. & [44] \\
\hline 3 & a 29 & 1 & $P$. aeruginusa & [18] \\
\hline 4 & a54 & 1 & Vibrio fischeri & [16] \\
\hline 5 & a57 & 1 & Microbacterium sp. & [5] \\
\hline 6 & a 40 & 1 & P. aeruginosa YS-7 & [63] \\
\hline 7 & $a, b 143$ & 1 & Pseudomonas & [64] \\
\hline 8 & ${ }^{a} 66$ & 1 & Eremothecium Ashbyii & [61] \\
\hline
\end{tabular}




\begin{tabular}{|c|c|c|c|c|}
\hline 9 & a,b32 & 1 & Rhizopus oryzae & [65] \\
\hline 10 & a 40 (I) and 43 (II) & 2 & P. cyclopium & [66] \\
\hline 11 & a34 & 1 & B. thermoleovorans ID-1 & [67] \\
\hline \multicolumn{5}{|c|}{${ }^{a}$ Molecular characteristics based on SDS-PAGE } \\
\hline \multicolumn{5}{|c|}{ bMolecular characteristics based on gel Chromatography } \\
\hline
\end{tabular}

Table 2: Shows the molecular weights of various microbial lipases.

\section{Physical Properties}

Molecular interactions between the substrate and the enzyme molecules may enhance the catalytic activity of the enzyme. Temperature and ionic strength of the reaction medium has relatively affected enzyme catalysis. Every enzyme, depending on the source and molecular structure has the exact temperature and $\mathrm{pH}$ of optimum catalysis.

\begin{tabular}{|c|c|c|c|c|}
\hline & Optimal pH & Optimal Temp & Source & Ref \\
\hline 1 & 10.0 & 40 & Pseudomonas & [64] \\
\hline 2 & 7.0 & 30 & Eremothecium Ashbyii & [61] \\
\hline 3 & 9.0 & 50 & Anoxybacillus flavithermus & [17] \\
\hline 4 & 7.0 & 30 & $P$. aeruginosa & [41] \\
\hline 5 & 7 & 36 & Staphylococcus & [37] \\
\hline 6 & 9 & 50 & Microbacterium sp. & [5] \\
\hline 7 & 8 & 30 & Vibrio fischeri & [16] \\
\hline 8 & 5 & 30 & Emericella nidulans & [55] \\
\hline 9 & 6.9 & 55 & $P$. aeruginusa & [18] \\
\hline 10 & 7 & 36 & Bacillus sp. & [44] \\
\hline 11 & 9.0 & 45 & $P$. aeruginosa $P S-X$ & [28] \\
\hline
\end{tabular}

Table 3: A summary of the effect of temperature and $\mathrm{pH}$ on enzyme catalyzed reactions.

The variation in the physical properties could be as a result of variation in the nature of the coded amino acids in the primary structures.

\section{Chemical Properties}

\section{Effect of solvents}

Here we are to mainly focus on the effect of some recognized and possible exposed organic solvents on lipases. In addition to esterification of long chain fatty acids and glycerol into triacylglycerides, as well as acting on other reactions such as transesterification and alcoholysis makes lipases a great biocatalyst of interest in organic chemistry and evaluating their stability in organic media is essential for further reaction design such as in biodiesel production $[14,68]$. Lipase immobilized on octyl derivative was very stable in glycerol. From the report of this research, the immobilized lipase showed $93.11 \%$ while in cyclohexane the lipase showed $48.90 \%$ residual activity but no activity was observed in acetonitriles, ethanol and tert-amyl alcohol [14].
Hexanol and butanol of $5-10 \%(v / v)$ concentration reduced the activities of lipase from $R$. miehei and $R$. oryzae but low concentrations of methanol, ethanol, propanol and isopropanol had no considerable effect on the p-NPP hydrolysis. The $R h$. Oryzae lipase was sensitive to the presence of isopentanol. There was observable and slight increase in pNPP hydrolysis by the lipase from $R$. miehei. Overall, the two enzymes were more stable in methanol and ethanol at higher concentrations than other alcohols tested [68]. Addition of $70 \%$ methanol showed maximum lipolytic activity while 2-propanol showed the minimum activity by lipase from Microbacterium $s p$ isolated from marble mining rock, New Delhi [5]. Methanol also improved the stability of lipase sourced from Photobacterium lipolyticum [69]. The reason maybe be attributed to the hydrophilicty or reduced bulkiness of methanol which imposed flexible attributes on the lid of the enzymes.

\section{Effects of detergents and bleaching agents}

Ionic detergents such as sodium deoxycholate and sodium taurocholate stabilized the activity of lipase from thermophilic 
Anoxybacillus flavithermus HBB134 to approximately 100\% while sodium dodecyl sulfate reduced it activity [17]. SDS and triton X-100 increased the activity of Microbacterium $s p$ lipase, while the addition of Tween 20 and Tween 80 inhibited the enzyme [5]. The same result was obtained for the Cynobacterium spirulina plantensis when treated with SDS [70]. Schmidt-Dannert et al. [71] reported a reduction of lipolytic activity in the presence of Tween 20 and Tween 80. Bakir and Metin in 2016 [17] also reported a reduction in the activity of thermophilic Anoxybacillus flavithermus HBB134 lipase in the presence of Triton X-100, Tween 20, Tween 80 and Brij 35. Bleaching agents such as $\mathrm{H}_{2} \mathrm{O}_{2}$ and $\mathrm{NaOCl}$ inhibited the activity of lipase sourced from thermophilic Anoxybacillus flavithermus HBB134 [17]. Lipolytic activity of lipase from a new strain of Pseudomonas aeruginosa SRT9 experienced a decrease in the presence of the following surfactants: SDS, Tween 60, Triton X-100 and a slight decrease in the presence of sodium deoxycholate while their activity increases in the presence of Tween-20, Tween-40 and Tween-80 [18].

\section{Effect of metal ions and chelators}

Presence of some metal ions is not inevitable in the medium where lipase lipolysis occurs. Some lipases are metalloenzymes and hence it is necessary to discuss the effect of some these metal ions on them.
$\mathrm{Na}^{+}$had no effect on the activities of lipase sourced from Pseudomonas aeruginosa SRT9 [18] and also lipase sourced from Vibrio fischeri [16]. $\mathrm{Ca}^{2+}$ slightly increased the activity of lipase from Pseudomonas aeruginosa SRT9 [18]. Meanwhile, Rajintha et al. reported that $\mathrm{Ca}^{2+}$ had no effect on lipase from Vibrio fischeria. $\mathrm{Fe}^{2+}$, $\mathrm{Ag}^{+}, \mathrm{Cu}^{2+}, \mathrm{Hg}^{+}, \mathrm{Pb}^{2+}$ and $\mathrm{Zn}^{2+}$ reduced the activity of lipase from a new strain of Pseudomonas aeruginosa SRT9 [16]. $\mathrm{Li}+, \mathrm{Na}^{+}$and $\mathrm{NH}^{4+}$ increased the enzyme's activity slightly whereas $\mathrm{Hg}+, \mathrm{Zn}^{2+}, \mathrm{Fe}^{3+}, \mathrm{Pb}^{2+}$ and $\mathrm{Al}^{+}$at the high concentration strongly inhibited the activity of lipase from thermophilic Anoxybacillus flavithermus HBB134 [17]. Similar result was obtained from lipases of Bacillus $s p$ [72], Bacillus thermoleovoraus CCR11 [73] and Acinetobacter sp RAG-1 for $\mathrm{Hg}^{+}$.

EDTA is a metal chelator, which is responsible for chealting metals making them not available in the reaction medium. This may reduce or enhance the lipase activity depending on the nature of the enzyme. thermophilic Anoxybacillus flavithermus HBB134 lipase was reported to retain $96 \%$ of its activity after incubation for one hour with EDTA at $5 \mathrm{mM}$ [17]. Lipase activity was inhibited at $49.3 \%$ in the presence of EDTA [5].

\begin{tabular}{|c|c|c|c|c|c|c|c|}
\hline & $\mathrm{Km}$ & Vmax & Kcat & Kcat $/ \mathrm{Km}$ & Substrate & Source & Ref \\
\hline 1 & $3.2 \mathrm{mM}$ & $50 \mu \mathrm{M} / \mathrm{min} / \mathrm{mg}$ & - & - & p-NPP & Pseudomonas & [64] \\
\hline 2 & $4612 \mu \mathrm{M}$ & $194 \mu \mathrm{M} / \mathrm{min}$ & $1949 \mathrm{~min}^{-1}$ & 0.423 & p-NPB & Aspergillus & [59] \\
\hline 3 & $781 \mu \mathrm{M}$ & $5.51 \mu \mathrm{M} / \mathrm{min}$ & $55.1 \mathrm{~min}^{-1}$ & 0.070 & $\mathrm{p}-\mathrm{NPL}$ & Aspergillus & [59] \\
\hline 4 & $5492 \mu \mathrm{M}$ & $273 \mu \mathrm{M} / \mathrm{min}$ & $2378 \mathrm{~min}^{-1}$ & 0.433 & p-NPB & E.coli CalB & [59] \\
\hline 5 & $915 \mu \mathrm{M}$ & $6.25 \mu \mathrm{M} / \mathrm{min}$ & $62.5 \mathrm{~min}^{-1}$ & 0.068 & p-NPL & E.coli CalB & [59] \\
\hline 6 & $178 \mu \mathrm{M}$ & $172 \mathrm{U} / \mathrm{mg}$ & $409 s^{-1}$ & 2.3 & Tributyrin & Pseudomonas & [64] \\
\hline 7 & $0.6 \mathrm{mM}$ & $322.5 \mathrm{mM} / \mathrm{min} / \mathrm{mg}$ & - & - & p-NPP & Emericella nidulans & [74] \\
\hline 8 & $1.11 \mathrm{mM}$ & $0.055 \mathrm{mM} / \mathrm{min}$ & - & - & Triolein & P. aeruginusa & [18] \\
\hline 9 & $0.11 \mathrm{mM}$ & $16 \mathrm{mM} / \mathrm{min}$ & - & - & $\mathrm{p}-\mathrm{NPL}$ & $P$. aeruginusa & [18] \\
\hline 10 & 0.037 & $188.6 \mathrm{mM} / \mathrm{min}$ & - & - & p-NPP & $P$. aeruginusa & [18] \\
\hline
\end{tabular}

Table 4: A summary of kinetic parameters of microbial lipases.

\section{Kinetic Properties}

\section{Industrial applications of microbial lipases}

The following industries have exploited the versrtile catalytic properties of lipase in their downstream processes.

Detergent industries: Detergent industries rank very high in the application of lipases and other hydrolases for improvement of their products. Since lipases attack lipids, some fatty acyl soils can be removed through the lipolytic action of lipases. Fatty acyl soils could be found in form of sweat, lipstick, fry fats, butter, sauces etc. [38]. The use of lipases in detergents could reduce the washing period, agitation and temperature, hence prolongs the life span of the textile materials and provides a habitable environment for living things. Lipases have been used in production of dishwashing detergents which brings down the quantity of surfactants used in the detergent production. Lipases can also be used as an additive during shampoo formulation to enhance removal of over-stayed oil in the hair, improving healthy hair and reducing dandruff on the hair.

Ideal qualities of detergent lipases are:

- Low substrate specificity

- Stability under washing condition

- Resistance to surfactant's denaturation and proteolysis by proteases.

Pulp and paper industry: The major application of lipases in pulp and paper industry is for "depitching" process, i.e. removal of "pitch" from the pulp during paper making [38]. Pitch is generally described as the hydrophobic components of wood (triglycerides and waxes). One of the major problems faced by paper industries is the pitch removal [38]. These lipid components appear as sticky deposits in the paper machines and cause holes and spots in the final paper. Lipases 
hydrolyze pitch into glycerol and free fatty acid which are soluble in water leading to their ease of washing away from the machines [38]. Lipases in paper industry can generally increase the pulping rate of pulp, increase whiteness and intensity, decrease chemical usage, prolong equipment life, reduce pollution level of waste water, save energy and time and reduce composite cost [7].

Leather industry: The hides and skins contain proteins and fat in the collagen fibres. One of the major steps in leather production is soaking the hides and skins. This is done to free them from common salt and protein substances such as blood. This step is taken before the tanning step and the rational is to ensure smooth tanning process of the hides and skins. To remove the proteins, proteases are needed. Proteolytic enzymes facilitate both the emulsification of natural fat by hydrolyzing the wall of fat cells and soaking operation [7]. To degrade the emulsified fats, lipases are needed; also since they are specific in their action, lipases will leave the leather undamaged. For sheep skins, the use of solvent for degreasing is now being replaced by the use of lipases and surfactants [7].

Cosmetics industry: Some ester compounds have been applied in the production of some personal care products, these esters may include but not restricted to isopropyl myristate, isopropyl palmitate and 2-ethylhexyl palmitate for use as an emollient in personal care products such as skin and sun-tan creams, bath oils etc. [7]. It has been reported that in the absence of water, lipases catalyze esterification. It has been shown that products made by this process has been known for their higher quality compared to the ones produced using the commonly used acid catalysts.

Lipases in biodiesel production: Biodiesel can be produced with a variety of feedstock including refined bleached deodorized (RBD) edible vegetable oils, animal fats and waste cooking oils. The choice of feedstock depends mainly on the geographical distribution [75] and price, which might amount up to $80 \%$ of production, costs [76]. Biodiesel is currently mostly produced at commercial scale utilizing alkali, mainly sodium hydroxide [77,78]. Process limitations such as presence of soap-forming free fatty acids (FFAs) in quantities above $0.5 \%$ are considered drawbacks of chemical biodiesel [75]. Furthermore, the by-products and waste water from the process act as potential environmental pollutants [78]. An acid catalyzed pretreatment becomes necessary prior to methanolic transesterification of crude oil which normally contains $>15 \%$ FFA in order to reach $90-99 \%$ biodiesel yield [79]. The use of non-specific and 1,3-specific lipases that can catalyze both esterification and transesterification of triacylglycerols in the oil and yield cleaner by-products as an alternative to harmful and hard to manage acid or alkali catalyst has been extensively documented [75].

Immobilized, non-specific candida Antarctica lipase B (Novozyme 435) has been the most commonly investigated enzymatic catalysts for Jatropha biodiesel production [80]. Immobilized lipase from Microbacterium $s p$. has been applied in the production of biodiesel from agal oil [5].

Lipases in food industries: One of the major needs of food industries is improved organoleptic properties of their finished products. Flavors and emulsifiers serve this need. Aside carboxylic esters hydrolysis, lipases catalyze esterification in the absence of water and presence of fatty acid and alcohol. Esters of short and medium chain carboxylic acids and alcohol moieties synthesized by lipases play a relevant role in the food industries as flavor and aroma constituents. Esterification by lipases appears to be an attractive alternative to bulk chemical routes. In fact, ester synthesis using lipase takes place in a mild condition of temperature, pressure and $\mathrm{pH}$ [81]. It has been noted that chemical catalysis is harsh and leads to unwanted products as when compared to biocatalysis hence the gentility and safety of the biocatalysts make them novel molecules for food industries.

Lipases are extensively used in dairy industry for the hydrolysis of milk fat. The dairy industry uses lipases to modify the fatty acid chain lengths to enhance the flavors of various cheeses [81]

Immobilized lipases are fast, efficient, accurate and cost effective as sensors for the qualitative determination of triacylglycerol. This application is important in the food industry, especially in fats and oils beverages, soft drinks, and pharmaceutical industries and also in clinical diagnosis [82]. The basic concept of using lipases as biosensors is to generate glycerol from the triacyglycerol in the analytical sample and to quantify the released glycerol by chemical or enzymatic method [83].

Immobilized microbial lipases have been effectively applied in the production of polyunsaturated fatty acids (PUFAs), such as omega-3, which is important in the food industries. PUFAs are found mostly in marine-derived products and can be obtained by hydrolysis or alcoholysis of fish oils catalyzed by lipases [14]. Omega-3 is a nutrient that promotes positive effects in human health, constituting an increasing market of dietary supplements and neutraceuticals that contain these PUFAs. PUFAs play a vital role in brain and retina improvement thereby enhances learning ability, mental development and visual acuity in young people. PUFAs are also required in adults and the aging individuals for protection against cardiovascular diseases and improving muscle function in older women $[84,85]$.

Immobilized lipase from Penicillium $s p$. section Gracilenta (CBMAI 1583 ) isolated from soil at the Atlantic Rainforest region (Sao Paulo State, Brazil) [86] was applied in the production of eicosapentaenoic acid and docosahexaenoic acids from Sardine oil hydrolysis [14].

Lipases in pharmaceutical industries: The use and preparation of chiral pharmaceutical principles as single enantiomers is one of the most relevant goals in pharmaceutical science. For chiral drugs, opposite enantiomers act with different biological properties and the distomer could give undesirable effects. Ibuprofen and ketoprofen are important members of the class non-steroidal anti-inflammatory drugs (NSAIDs), employed as racemate in pharmaceutical formulations, but have their pharmacological activity mainly in belonging in $S(+)$ enantiomers $[87,88]$.

In organic solvents, lipases can be more enantioselective and the solubility of hydrophobic substrate can be enhanced [89,90]. Possible approaches to the enzymatic resolution of chiral profens include the enantioselective hydrolysis [67], tranesterification or the direct esterification in non-aqueous medium using microbial lipases. Lipases from Candida rugosa, Candida antarctica and Rhizomucors miehei have been used to resolve the enantiomers of ibuprofen [91], naprofen [92] and Suprofen [93].

The use of Aspergillus niger lipase in the resolution of (R,S)Ibuprofen and (R,S)-Ketoprofen has been reported in some literatures [88].

\section{Conclusion}

There are enormous demand for green products in the present generation and microbes have been an effective cell factory that 
harbors novel biocatalysts to serve the present need. It is expected that the demand will increase rapidly in time to come. There is need to enhance the production of lipases and also improve on them so as to meet the increasing demand for this enzyme.

\section{References}

1. Fariha H, Aamer AS, Abdul H (2006) Industrial Applications of Microbial Lipases. Enzyme and Microbial Technology 39: 235-251.

2. UnderkoflerLA,Barton RR, Rennest SS (1958) Production of microbial enzymes and their applications. Appl Env Microbiol 6: 212- 221.

3. Deb P, Talukder SA, Mohsina K, Sarker PK, Sayem SMA (2013) Production and partial characterization of extracellular amylase enzyme from Bacillus amyloliquefaciens P- 001. Springer Plus 2: 154-165.

4. Das S (2011) Biotechnological applications of industrially important amylase enzyme. International Journal of Pharmacology and Biological Scienc 2: 486- 496.

5. RituT, Jyoti S, RandhirKB, Indu ST (2014) Isolation, Purification and Characterization of Lipase from Microbaterium sp. and its Application in Biodiesel Production. Energy Procedia 54: 518-529.

6. Kirk O, Borchert $\mathrm{T} \mathrm{V}$,FuglsangC C (2002) Industrial enzyme applications. Current. Curr Opin Biotechnol 13: 345-351.

7. Berhanu A, Amare G (2012) Microbial Lipases and Their Industrial Applications: Review. Biotechnology 11: 100-118.

8. Wiseman A (1995) Introduction to Principles. In: Handbook of Enzyme Biotechnology (3rdEdn.) Ellis Horwood Ltd., T.J Press Ltd, Padstow, Cornwall, UK. pp: 3-8.

9. Konsoula Z, Liakopoulou-Kyriakides M (2007) Co-production of alphaamylase and beta-galactosidase by Bacillus subtilis in complex organic substrates. Bioresour Technol 98: 150-157.

10. Sundarram, A, Murthy TP (2014) a-Amylase Production and Applications: A Review. JAEM 2: 166-175.

11. Sztajer H, Maliszewska I, Wieczorek J (1988) Production of exogenous lipase by bacteria, fungi and actinomycetes. Enzyme and Microbial Technology10: 492-497.

12. Lotti A (2007) Lipases: Molecular Structure and Functions in: Polaina, J and Andrew, P.M (eds) Industrial Enzymes Structure, Function and Applications. Springer pp: 263-280.

13. Ollis DL, Cheah E, Cygler M, Dijkstra B, Frolow F, et al. (1992) The alpha/ betahydrolase fold. Protein Eng 5: 197-211.

14. Daniela FM, Wilson GM, Cesar RFT, Sonia M, Benevides CP, et al. (2017) Immobilization of Lipase from Penicillium sp Section Gracilenta (CBMAI 1583) on Different Hydrophobic supports: Modulation of Functional Properties. Molecules 22: 339.

15. Kobayashi S (2010) Lipase-catalyzed Polyester Synthesis- A Green Polymer Chemistry. Proc Jpn Acad Ser B Phys Biol Sci 86: 338-365.

16. Ranjitha P, Karthy ES, Mohankumar A (2009) Purification and Characterization of Lipase from Marine Vibrio fischeri. International Journal of Biology 1: 48-56.

17. Bakir ZB, Metin K (2016) Purification and Characterization of an AlkaliThermostable Lipase from Thermophilic Anoxybacillus Flavithermus HBB 134. J Microbiol Biotechnol 26: 1087-1097.

18. Prita SB, Ragini GB, Srinivasa RR, Khobragade CN (2009) Purification and characterization of extracellular lipase from a new strainPseudomonas aeruginosa SRT9. Brazilian J Micobiology 40: 358-366.

19. Chen SJ, Cheng CY, Chen TL (1998) Production of an alkaline lipase by Acinetobacter radioresistens. J Ferment Bioeng 86: 308-312.

20. Anguita J, Rodriguez-Aparicio LB, Naharro G (1993) Purification, gene cloning, amino acid sequencing analysis and expression of an extracellular lipase from an Aeromonas hydrophila human isolate. Appl Environ Microbiol 59: 2411-2417.

21. Lee HK, Ahn MJ, Kwak SH, Song WH, Jeong BC (2003) Purification and Characterization of Cold active Lipase from Psychrotrophic Aeromonas sp. LPB4. J Microbiol 41: 22-27.
22. Roble-Medina A, Gonzalez-MorenoRA, Esteban-Cerdun L, MolinaGrima E (2009) Biocatalysis: Towards ever greener biodiesel production. Biotechnol Adv 27: 398-408.

23. Zeng Z, Xiao X, Wang P Wang F (2004) Screening and Characterization of Psychrotrophic, Lipolytic Bacteria from deep-sea Sediments. Journal of Microbiology and Biotechnology 14: 952-958.

24. Kaieda M, Samukawa T, Kond A, Fukuda H (2001) Effect of Methanol and water contents on production of Biodiesel fuel from plant oil catalyzed by various lipases in a solvent-free system. J Biosci Bioeng 91: 12-15.

25. Fischer L, Bromann R, Kengen S, de Vos W, Wagner F (1996) Catalytic Potency of $\beta$-glucosidase from the extremophile Pyrococcus furiosus in glucoconjugate synthesis. Biotechnology (N Y) 14: 88-91.

26. Charoenpanicha J, Suktanaraga S, Toobbuch N (2011) Production of a thermostable lipase by Aeromonas sp. EBB-1 isolated from marine sludge in Angsila, Thailand. Science Asia 37: 105-114.

27. Uttatree S, Winayanuwattikun P, Charoenpanicha J (2010) Isolation and Characterization of a novel thermophilic organic solvent stable lipase from Acinetobacter baylyi. Appl Biochem Biotechnol 162: 1362-1376.

28. Saeed HMZ, Aghloul TI, Khalil AI, Abdelbaeth MT (2005) Purification and characterization of two extracellular lipases from Pseudomonas aeruginosa Ps -x. Polish Journal of Microbiology 54: 233-240.

29. Gilbert JE, Cornish A, Jones CW (1991) Purification and properties of extracellular lipase from Pseudomonas aeruginosa EF2. J Gen Microbiol 137: 2223-2229.

30. Sidhu P, Sharma R, Soni SK, Gupta JK (1998) Production of extracellular alkaline lipase by a new thermophilic Bacillus sp. Folia Microbiol 43: 51-4.

31. Rees GD, Robinson BH (1995) Esterification reactions catalysed by Chromobacterium viscosum lipase in CTAB-based microemulsion system. Biotechnol Bioeng 45: 344-5.

32. Long K, Ghazali HM, Ariff A, Ampon K, Bucke Ce, et al. (1996) In-situ crosslinking of Aspergillus flavus lipase: improvement of activity, stability and properties. Biotechnology Letters 18: 1169-74.

33. Mayordoma I, Randez-Gil F, Prieto JA (2000) Isolation, purification and characterization of a cold active lipase from Aspergillus nidulans. J Agric Food Chem 48: 105-9.

34. Brocca S, Schmidt-Dannert C, Lotti M, Alberghina L, Schmid RD, et al. (1998) Design, total synthesis and functional over expression of the Candida rugosa lip 1 gene coding for a major industrial lipase. Protein Sci 7: 1415-1422.

35. Sommer P, Bormann C, Gotz F (1997) Genetic and biochemical characterization of a new extracellular lipase from Streptomyces cinnamomeus. Appl Environ Microbiol 63: 355360.

36. Samadi AYR, Azak CN, Salleh AB, Yunus WM, Ampon K, et al. (1989) A plate assay for primary screening of lipase activity. Journal of Microbiological Methods 9: 51-56.

37. Sirisha E, Rajaseker N, Narasu ML (2010) Isolation and Optimization of lipase producing Bacteria from oil contaminated soils. Advances in Biological research 4: 249-252.

38. Kouker G, Jaeger KE (1987) Specific and Sensitive plate assay for bacterial lipase. Appl Environ Microbiol 53: 211-213.

39. Sierra G (1957) A simple method for the detection of lipolytic activity of microorganisms and some observations on the influence of the contact between cells and fatty substrates. Antonie van Leeuwenhoek 23: 15-22.

40. Karnetova J, Mateju J, Rezanka T, Prochazka P, Nohynek M, et al. (1984) Estimation of lipase activity by the diffusion plate method. Folia Microbiol (Praha) 29: 346-347.

41. Benattouche Z, Abbouni B, Bachir RG (2012) Isolation, Purification and Properties of Lipase from Pseudomonas aeruginosa. African Journal of Biotechnology 11: 12415-12421.

42. Jensen RG (1983) Detection and determination of lipase (acylglycerol hydrolase) activity from various sources. Lipids 18: 650-657.

43. Veerapagu M, Narayanan SA, Ponmurugan K, Jeya KR (2013) Screening, Selection, Identification and Optimization of Bacterial Lipase from Oil 
Spilled Soil. Asian Journal of Pharmaceutical and Clinical Research 6 63-67.

44. Priya KU, Reddy BI (2015) Isolation, Optimization and Partial Purification of Lipase Enzyme. Biotechnol Appl Biochem 6: 2156-2171.

45. Kasra-Kermanshahi R, Mobarak-Qamsari E, Moosavi-nejad Z (2011) Isolation and Identification of a novel, lipase producing bacterium, Pseudomonas aeruginosa KM110. Iran J Microbiol 3: 92-98.

46. Kulkarni N, Gadre RV (2002) Production and Properties of an Alkaline, Thermophilic Lipase from Pseudomonas fluorescens NS2W. J Ind Microbiol Biotechnol 28: 344-348.

47. Khemika L, Angkhameen B, Hataichanoke N (2012) Investigation of Isolated Lipase Producing Bacteria from Oil-contaminated Soil with Proteomic Analysis of its Proteins Responsive to Lipase Inducer. Journal of Biological Sciences 12: 161-167.

48. Gulati R, Saxena RK, Gupta R (2000) Fermentation and downstream processing of lipase from Aspergillus terreus. Process Biochemistry 36:149-155.

49. ElibO M, Ozer D (2001) Influence of oxygen transfer on lipase production by Rhizopus arrhizus Process Biochemistry 36: 325-329.

50. Ayinla ZA, Ademakinwa AN, Agboola FK (2017) Studies on the Optimization of Lipase Production by Rhizopus sp. ZAC3 Isolated from the Contaminated Soil of a Palm Oil Processing Shed. J App Biol Biotech 5: 030-037.

51. Maia MMD, Heasley A, Morais MMC, Melo EHM, Morais MA, et al (2001) Effect of culture conditions on lipase production by Fusarium solani in batch fermentation. Bioresour Technol 76: 23-27.

52. Yang X, Wang B, Cui F, Tan T (2005) Production of lipase by repeated batch fermentation with immobilized Rhizopus arrhizus. Process Biochemistry 40: 2095-2103.

53. Rehman S, Bhatti HN, Bhatti IA, Asgher M (2011) Optimization of process parameters for enhanced production of lipase by Penicillium notatum using agricultural wastes. African Journal of Biotechnology 10:19580-19589.

54. Amin F, Bhatti HN, Rehman S (2011) Optimization of growth parameters for lipase production by Ganoderma lucidum using response surface methodology. African Journal of Biotechnology 10: 5514-5523.

55. Lanka S, Latha NL (2015) Purification and Characterization of new cold active lipase Enl A from Emericella nidulans NFCCI 3643. African Journal of Biotechnology 14: 1897-1909.

56. Sun SY, Xu Y (2008) Solid-state fermentation for 'whole-cell synthetic lipase' production from Rhizopus chinensis and identification of the functional enzyme. Process Biochemistry 4: 219-224.

57. Edwinoliver NG, Thirunavukarasu K, Naidu RB, Gowthaman MK Kambe TN, et al. (2010) Scale up of a novel tri-substrate fermentation for enhanced production of Aspergillus niger lipase for tallow hydrolysis. Bioresour Technol 101: 6791-6796.

58. Prasanth Kumar PM ,Valsa AK (200) Optimization of culture media and cultural conditions for the production of extracellular lipase by Bacillus coagulans. Indian Journal of Biotechnology 6: 114-117.

59. Kerstin B, Julia M, Hermann G, Nermann EG (2006) Functional expression of Candida antarctica lipase B in Eschericha coli. J Biotechnol 125: 474-483.

60. Mohsen M, Zargharm S, Azadeh E, Ahmad RS, Mohammad AF, et al. (2016) Enhancing Activity and Thermostability of Lipase A from Serratia marcescens by site-directed Mutagenesis. Enzyme Microb Technol 93: 18-28.

61. Kalindhi K, Vijayalakshmi S (2015) Isolation and Purification of Lipase from the Riboflavin Overproducing Fungus Eremothecium ashbyii. Journal of the Analgesics 3: 1-8.

62. Laemmli UK (1970) Cleavage of structural proteins during the assembly of the head of bacteriophage T4. Nature 227: 680-685.

63. Shabtai Y, Daya-Mishne N (1992) Production, purification and properties of a lipase from bacterium (Pseudomonas aeruginosa YS-7) capable of growing in water-restricted environments. Appl Environ Microbiol 58 174-80.
64. Lambit K, Pranab G (2002) Isolation of a pseudomonas Lipase Produced in pure hydrocarbon substrate and its application in the synthesis of Isoamyl acetate using membrane-immobilized lipase. Enzyme Microbial Technology 31: 727-758.

65. Hiol A, Jonzo MD, Rugani N, Druet D, Sarda L, et al. (2000) Purification and characterization of an extracellular lipase from a thermophilic Rhizopus oryzae strain isolated from palm fruit. Enzyme Microb Technol 26: 421-30.

66. Chahinian H, Vanot G, Ibrik A, Rugani N, Sarda L, et al. ( 2000) Production of extracellular lipases by Penicillium cyclopium purification and characterization of partial acylglycerol lipase. Biosci Biotechnol Biochem 64: 215-222.

67. Kim MG, Lee SB (1996) Enzymatic resolution of racemic ibuprofen by lipase-catalyzed esterification reaction: Effects of water content and solid supports. J Ferment Bioeng 81: 269-271.

68. Tako M, Kotogan A, Papp T, Kadaikunnan S, Alhabi NS, et al. (2017) Purification and Properties of Extracellualr Lipase with Transesterification Activity and 1,3-Regioselectivity from Rhizomucor miehei and Rhizopus oryzae. J Microbiol Biotechnol 22: 277-288.

69. Yang KS, Sohn JH, Kim HK (2009) Catalytic properties of a lipase from Photobacterium lipolyticum for biodiesel production containing a high methanol concentration. J Biosci Bioeng 107: 599-604.

70. Demir BS, Kess T (2010) Purification and characterization of lipase from Spirulina platensis. Journal of Molecular Catalysis Enzymology 64: 123-128.

71. Schmidt-Dannert C (1994) Screening, purification and properties of a thermophilic lipase from Bacillus thermocatenulatus. Biochim. Biochim Biophys Acta 1214: 43-53.

72. Nawani N, Kaur J (2000) Purification, characterization and thermostability of lipase from a thermophilic Bacillus sp. Mol Cell Biochem 206: 91-96.

73. Castro-Ochoa LD, Gómez RC, Alfaro VG, Ros RO (2005) Screening, purification and characterization of the thermoalkalophilic lipase produced by Bacillus thermoleovorans CCR11. Enzyme Microb Technol 37: 648-654.

74. Lanka S, Pydipalli M, Latha JNL (2015) Optimization of Process Variables for Extracellular Lipase Production from Emericella nidulans NFCCI 3643 Isolated from Palm Oil Mill Effluent (POME) Dump Sites Using OFAT Method. Research Journal of Microbiology 10: 38-53.

75. Abdulla R, Chan ES, Ravindra P (2011) Biodiesel production from Jatropha curcas: a critical review. Crit Rev Biotechnol 31: 53-64.

76. Christopher LP, Kumar H, Zambare VP (2014) Enzymatic biodiesel: challenges and opportunities. Applied Energy 119: 497-520.

77. Fjerbaek L, Christensen KV, Norddahl BA (2008) Review of the current state of biodiesel production using enzymatic transesterification. Biotechnol Bioeng 102: 1298-315.

78. Hama S, Kondo A (2013) Enzymatic biodiesel production: an overview of potential feedstock and process development. Bioresource Technology 135: 386-95.

79. Cesarini S, Diaz P, Nielsen PM (2013) Exploring a new soluble lipase from FAMEs production in water-containing systems using crude soybean oil as feedstock. Process Biochemistry 48: 484-487.

80. Francisco B, Luis M, Mathew C, Karla M (2015) Lipase-catalyzed Biodiesel Production and Quality with Jatropha curcas oil: exploring its Potential for Central America. J Biol Eng 9:12.

81. Aravindan R, Anbumathi P, Viruthagiri T (2007) Lipase application in food industry. Indian Journal of Biotechnology 6: 141-158.

82. Kynclova E, Hartig A, Schalkhammer T (1995) Oligonucleotide labeled lipase as a new sensitive hybridization probe and its use in bio-assays and biosensors. J Mol Recog 8: 139-145.

83. Pandey RK, Lakshmi T (2015) Microbial Enzymes Involved in Starch Processing Industries- a Review. Journal of Biological Science 4: 1-3.

84. Deckelbaum RJ, Torrejon C (2012) The Omega-3 Fatty Acid Nutritional Landscape: Health Benefits and Sources. J Nutr 142: 587S-591S. 
Citation: Ugo AK, Amara AV, Igwe CN, Kenechuwku U (2017) Microbial Lipases: A Prospect for Biotechnological Industrial Catalysis for Green Products: A Review. Ferment Technol 6: 144. doi:10.4172/2167-7972.1000144

Page 12 of 12

85. Da Boit M, Sibson R, Sivasubramaniam, Meakin S, Greig JR, et al. (2017) Sex differences in the effect of fish oil supplementation on the adaptive response to resistance exercise training in older people: A randomized control trial. American Journal of Clinical. Nutrition 105: 151-158.

86. Tauk-Tornisielo SM, Garlipp A, Ruegger M, Attili DS, Malagutti E, et al. (2005) filamentous fungi in Brazil. J Basic Microbiol 45: 7282.

87. Hernáiz MJ, Sanchez-Montero JM, Sinisterra JV (1994) Comparison of the enzymatic activity of commercial and semipurified lipase of Candida cylindracea in the hydrolysis of the esters of $(\mathrm{R}, \mathrm{S}) 2$-aryl propionic acids. Tetrahedron 50: 10749-10760.

88. Carvalho PO, Contesini FJ, Ikegaki M (2006) Enzymatic Resolution of $(\mathrm{R}, \mathrm{S})$-Ibuprofen and (R,S)-Ketoprofen by Microbial Lipases from Native and Commercial Sources. Braz J Microbiol 37: 329-337.

89. Chen CS, Sih CJ (1989) General aspects and optimization of enantioselective biocatalysis in organic solvents. The use of lipases. Angew Chem 28: 695.
90. Chen CS, Fujimoto Y, Girdaukas G Sih CJ (1982) Quantitative analyses of biochemical kinetic resolutions of enantiomers. J Am Chem Soc 104: 7294-7299.

91. Kumar I,Manju K, Jolly RS (2001) A new biocatalyst for the preparation of enantiomeically pure 2-arylpropionic acids.Tetrahedron: Assymetry 12: 1431-1434.

92. Nakayama K (1981) Sources of industrial microorganisms. In: Rehm HJ, Reed G (eds). Biotechnology, Microbial Fundamentals, Verlag Chemie, Veinheim, pp: 355-410.

93. Santaniello E , Ferraboschi P, Grisenti P (1993) Lipaze-catalyzed transesterification in organic solvents: Applications to the preparation of enantiomerically pure compounds. Enzyme and Microbial Technology 15: 367-382. 